\title{
SCIENTIFIC RESEARCH UNDER AN INTEGRATED PERSPECTIVE OF THE HUMAN BEING
}

Pardini F. Scientific research under an integrated perspective of the human being. Arq Gastroenterol. 2016;53(1): 2.

The investigation of the pathophysiological phenomena, whether anatomical, biochemical, immunological, morph functional or therapeutic processes, involved and modified in all human ailments, looks for basic, more sophisticated or innovative knowledge in medical sciences.

The international diversity of clinical trials, from greater to lesser expression in the scientific community, is the result from this anxiety of learning, aiming at the development and progress of the "sick process" knowledge.

The Gastroenterology specialty has experienced a proliferation of studies of digestive diseases, integrating acquisitions of innovative knowledge of subspecialties such as endoscopy, motility, image diagnosis, surgery, organ transplants, microbiology and pharmacology, being the Archives of Gastroenterology one of the representatives of the medical literature research diffusers.

A particularity that distinguished from its partners, already recognized internationally, since his birth in the sixties of the last century, lies in the journal intention to encourage the research of emotional components, from psychological and behavioral order associated to these disturbances called organics, expressed by the individual in test.

It is obvious that this totalitarian and holistic approach of the individual or of the clinical situation addressed, has always been based on scientific principles and concepts used by researchers in the human behavior and mind, integrating them to the biological processes in question.

This was a legacy to the following generations and always increasingly recognized, from our founder and master, Prof. José Fernandes Pontes, always supportive and diffuser of psychosomatic cause in human illness.

The current edition of the Archives reaffirms this commitment and scientific history of this approach, publishing two excellent works. Though not pioneers, they propose to research behavioral and emotional phenomena of patients and their family, bystanders involved directly or indirectly with the expectation of receiving a liver transplant and a depression incidence during $\mathrm{C}$ hepatitis treatment ${ }^{(1,2)}$.

Aside from the rigorous and scientific study in the phenomenology approach in liver pathology involved, the major objective of both was the analysis of the feelings of anxiety, depression, grief, fear, in addition to the associated comorbidities, generated by the transplant candidates and in their families or in C hepatitis treatment. Such feelings are interpreted from criteria and rating scales for depression and anxiety recognized and accepted internationally, with individual adjustments for each country where carried out.

The application of these investigative methods and parameters in a disease that requires an extreme therapeutic conduct reveals a "face" dormant and not expressed from the subjective components of the individual(s) involved directly or indirectly. The first goals of the research, consists in mapping these objective, behavioral, environmental and relational instances, that certainly, are involved in the results and/or expectations of those individuals in the face of such medical conduct proposed.

Comply with this global attention methodology applied to the medical sciences, the provision required and undeniable that the essential nature of the medical act must be humanist and therefore the therapy must be structured according to the sick person, and not only organize, preventing or healing the illness, just from a pathological process.

The understanding that the somatic pathogenesis is universally committed with the psychological function, causes the outreach medical action in a complex process of social integration, which include the wellknown semiology, diagnostic and therapeutic acts, with elements of emotional life and irrational mind of the participants.

Fernando PARDINI*

Pardini F. A pesquisa científica sob uma perspectiva integradora do ser humano. Arq Gastroenterol. 2016;53(1):2.

\section{REFERENCES}

1. Sahin Y, Virit O, Demir B. Depression and anxiety in parents of children who are candidates for liver transplantation. Arq Gastroenterol. 2016,53(1):25-30

2. Vabo ILC, Ferreira LEVVC, Pace FHL. Depressive episode incidence in patients with chronic hepatitis C treated with pegylated interferon and ribavirin. Arq Gastroenterol. 2016,53(1):20-4.

* Editor Assistente da Arquivos de Gastroenterologia 